\title{
El etnólogo y sus fantasmas. Leiris en África ${ }^{1}$
}

\author{
FERNANDO GIOBELLINA BRUMANA \\ Universidad de Cádiz
}

A Maria do Carmo Brandão

\section{RESUMEN}

La Misión Dakar-Yibuti, bajo la dirección de Marcel Griaule, atravesó el continente africano entre 1931 y 1933. En sus filas se encontraba Michel Leiris, joven poeta que acababa de romper con la cúpula surrealista y pasaba por malos tiempos personales. Este artículo registra su experiencia en este viaje de descubrimiento de sí, del otro y de la etnografía. Representación y marginalidad, esos son los elementos que quedarán, tanto en L'Afrique fantôme como en sus otros escritos sobre los dogon y el culto zar.

\section{SUMMARY}

The Dakar-Djibouti expedition, led by Marcel Griaule, crossed Africa between 1931 and 1933. One of the participants was Michel Leiris, a young poet who had just severed his relations with the surrealist avantgarde and was in the throes of a personal crisis. This paper is about his experience in that journey of discovery of himself, of the other and of ethnography. Representation and margination: these are the themes that will endure in L'Afrique fantôme as well as in Leiris' other writings about the Dogon and the Zar cult.

Palabras clave: Etnografía francesa. Dogon. Etiopía. Culto zar. Representación.

Key words: French ethnography. Dogon. Ethiopia. Czar cult. Representation.

\footnotetext{
${ }^{1}$ Este artículo, en que me ocupo del relato autobiográfico que contiene L'Afrique Fantôme de Michel Leiris, forma parte de un trabajo de dimensiones mucho mayores, dedicado en buena medida al estudio de la Misión Dakar-Yibuti. Esta expedición, dirigida por Marcel Griaule, que atravesó el continente Africano de occidente a oriente en poco menos de un par de años, es considerada el acta del bautismo tardío de la etnografía francesa. Detrás de ella estaban Mauss, Rivet, el naciente Museo del Hombre, así como los poderes intelectuales y coloniales de Francia. De hecho, y como en parte queda reflejado en este trabajo, era la aventura de un puñado de jóvenes con poca o ninguna formación etnográfica anterior: una suerte de híbridos entre Tintín y Tartarín.
}

RDTP, LVI, 2 (2001): 185-216 
Hemos leído ya las palabras de Griaule ${ }^{2}$, su programa de que los efectos de la Misión científica ayudasen a humanizar y racionalizar las relaciones coloniales. Pero en el campo, cara a cara con los portadores de esa cultura que debía ser rescatada, la situación de dominio se podía llevar al límite y sin adorno alguno. El carácter sublime al que la expedición aspiraba, además, no se compaginaba con la manera real en que las cosas se llevaron a cabo: chapuzas de principiantes, despistes, falta de objetivos claros, etc., es decir, algo normal para gente que se estaba iniciando en el oficio. L'Afrique Fantôme revelaría todo esto - y otras cosas, la escandalosa manera en que la Misión se apoderaba de los objetos para el Museo, las "patadas en el culo" de Griaule a nativos que lo irritaban (aunque quizás para éste haya sido aun peor que se conociera la patada en la entrepierna que recibió durante una reyerta con nativos etíopes), los golpes que el mismo Leiris quiso dar en momentos de furor ${ }^{3}$, las acaloradas aventuras sexuales de algunos de sus miembros (el rapto de una mujer, la introducción en el campamento de otra para que practicase sus artes felatorias, las visitas a prostíbulos, etc.) - de una manera insoslayable. E insoportable para Griaule. Pero L'Afrique... no es sólo, ni mucho menos, ese retrato poco embellecedor de las andanzas de la Misión; ni crítica ni autocrítica de la etnografía colonial, es el descubrimiento por sí mismo y en sí mismo de cómo son las cosas.

\section{1. ÁFRICA FANTASMA}

¿Cómo resumir, cómo comprimir, cómo dar una versión puntual de un diario, cuyo valor primero es la lenta extensión, su morosidad, ese continuo no saber, las contradicciones, las paradojas, las digresiones? Tarea imposible; lo más a lo que se puede —lo más a lo que puedoaspirar es a un cierto tránsito por él y sus alrededores.

\footnotetext{
${ }^{2}$ Las palabras de Griaule a las que me refiero, en las que habla de un boxeador negro panameño, Panamá Al Brown, que intervino en un combate para recaudar fondos para la expedición, son: "Al Brown sabrá poner sus puños al servicio de esta causa de interés universal: hacer posible entre los pueblos coloniales y los pueblos colonizados, gracias a un mejor conocimiento de la mentalidad de estos últimos, una colaboración más fecunda, que se ejerza en un plano menos brutal al mismo tiempo que más racionaln (nota de Griaule aparecida en el Paris-Soir del 14.IV.31, cit. en Jamin 1996: 27).

3 Tras uno de estos episodios, dice Leiris (1996: 202-203. 16.IX.31): "Y si me sigue jodiendo, le parto la jeta. Al ver hasta dónde yo mismo me impaciento con los negros, que me irritan, mido el grado de bestialidad al que podrán llegar, en sus relaciones con el indígena, aquellos que están agotados por el clima y a quienes no contiene ninguna ideología.
} 
Empecemos por lo más elemental. Las circunstancias editoriales de L'Afrique Fantôme: diversas ediciones salieron, todas en colecciones diferentes ${ }^{4}$, mostrando que su clasificación era difícil de resolver. Los efectos de su publicación: su acogida fue pésima, no ya por el gran público, sino por los más directos allegados a la Misión. Rivet la vio con disgusto, aunque se limitó, en forma muy pedante, a encontrarle defectos de forma. Una de estas observaciones era bastante ridícula: el haber confundido la bahía de Hudson con el estuario del río Hudson en el sueño registrado el 18.XI.1931. Mauss la consideró una obra poco seria, típica de un literato, que vendría a perjudicar los trabajos de campo posteriores. Algo similar fue lo que dijo el propio Griaule, a quien el libro había sido dedicado ${ }^{5}$, pero en estado de furia; las relaciones entre los amigos acabaron aquí.

${ }^{4}$ La de 1934 en Les Documents bleus, la de 1951 en Hors-Serie, la de 1968 en Blanche, la de 1981 en la Bibliothèque des sciences bumaines (aparecer en esta colección significaba para Leiris ser por fin reconocido como un etnólogo serio, profesional: "Me ha gustado como a un truhán muy contento si se le colgase la Legión de Honor" - Price y Jamin 1988: 48-), la de 1988 en Tel, la de 1996 en Quarto, todas en la casa Gallimard. Esta última está a cargo de Jean Jamin, el fundador de la revista Gradhiva y Secretario General de L'Homme tras la muerte de Pouillon, amigo de Leiris y una suerte de albacea literario suyo, su más profundo conocedor, en todo caso. A él debemos la edición de otros trabajos del poeta etnólogo, como el Journal de Chine (Gallimard, 1994), así como una entrevista junto a Sally Price que cito varias veces en este trabajo (Price y Jamin 1988).

Esta recopilación de textos - un volumen de casi 1500 páginas- no abarca la totalidad de la obra africana de Leiris; escritos claves ya publicados como La Langue secrète des Dogons de Sanga — de más de 500 páginas-, o el nunca publicado diario del viaje a Costa de Marfil, han debido ser descartados por razones editoriales. Miroir de l'Afrique alberga algún texto inédito, además de los dos grandes conocidos, el diario de la Misión Dakar-Yibuti y los trabajos redactados con el material recogido en Etiopía. De todas maneras, esta nueva edición vuelve obsoletas las otras. La gran ventaja de este L'Afrique Fantôme respecto a los anteriores radica en la extensa introducción y presentación de Jamin, además de sus numerosas notas aclaratorias, en los fragmentos de la correspondencia de Leiris con su mujer citados junto al diario en las fechas correspondientes y en muchas más ilustraciones fotográficas. Los textos sobre la posesión en Gondar ganan, en relación a la segunda edición de 1980, un texto introductorio de Jacques Mercier, un aparato de notas suplementario al brindado por Leiris y una obra gráfica inédita tomada de los cuadernos del autor, dibujos y acuarelas realizadas por dos agentes religiosos etíopes con los que trabajó Leiris. Miroir..., además, cuenta con varios índices de gran utilidad para quien deba orientarse en este libro gigante. En fin, que pocas veces en la historia de la antropología se ha publicado un texto con tanto cuidado.

5 Sólo su primera edición; las siguientes eliminaron la dedicatoria. De todas maneras, el rechazo de Griaule no fue una sorpresa. En carta a su mujer (Leiris 1996: 402. 8.IV.32) ya dice: "Si mi diario aparece, sin duda me cortará los puentes con Griaule, ya que es inadmisible desde el punto de vista oficialp; esta es la razón por la cual Leiris no mostró las pruebas de imprenta de L'Afrique... a Griaule. 
La mala fama del libro se extendió. En un informe del Ministerio de Educación en el que se rechazaba la posibilidad de adquirir ejemplares de la obra para repartir a bibliotecas bajo su jurisdicción se la calificaba así: "Obra cuya aparente inteligencia no se debe más que a una gran bajeza de sentimientom. Años más tarde, en 1941, el gobierno de Vichy prohibió su venta y mandó destruir los ejemplares sobrantes, aunque esta segunda orden pudo ser burlada por la casa editorial ${ }^{6}$.

Es difícil, sin embargo, pensar en L'Afrique... como en una obra maldita, condición más acorde con las de otros amigos de Leiris, Bataille para no ir más lejos, o el propio Artaud, a quien he dedicado otro estudio (Giobellina Brumana 2000). Aun cuando hable de las eyaculaciones de una cabra en el barco que llevaba a los expedicionarios a Dakar, sus propias poluciones nocturnas o sus elucubraciones - que no ejerciciossobre la masturbación, el despojo del patrimonio de los indígenas o una clasificación de clítoris que anticipa la de vaginas hecha por Henry Miller ${ }^{7}$, nada hay en ello que pretenda provocar. Si provoca, como en realidad provoca, es por su total falta de pretensión, por la desnudez de quien escribe ante sí mismo. L'Afrique... nada intenta. Sin embargo logra, o mejor, logramos nosotros sus lectores a través suyo. Un texto abierto por todas las costuras, expuesto a todos los vientos exteriores e interiores, un registro libre de lo vivido, visto, oído, sentido, pensado, soñado, hecho... prácticamente cada día entre el diecinueve de mayo de 1931 ("Partida de Burdeos a las 17.50") y el dieciséis de febrero de 1933 ("No me queda nada más para hacer, sólo cerrar este cuaderno, apagar la luz, echarme, dormirn), no incluía en sus páginas, no podría haberlo hecho, intención argumental alguna. Los argumentos son segundos, producto de la lectura, de la interpretación. L'Afrique... se presenta como un texto en bruto.

Texto en bruto, sí, pero nunca destinado a ser desconocido. El "diario de ruta" (como lo llamaba su autor en la primera presentación de un fragmento - Leiris 1933-) fue desde un comienzo un proyecto editorial explícito en el propio diario, donde una y otra vez se reflexiona sobre la

\footnotetext{
${ }^{6}$ Leiris siempre sospechó que Griaule estaba detrás de esa persecución. De hecho, los vínculos de éste con el régimen pro-nazi de Vichy hicieron que, tras la liberación, tuviese que afrontar la acusación de colaboracionista. Al parecer, fue Schaeffner -marido de Denise Paulme, amigo de Leiris- quien efectuó la denuncia. Para más detalles, cf. Byrne (2001).

${ }^{7}$ Enseñanzas de una vieja maliense encargada de las ablaciones: «[...] hay clítoris de mal augurio: aquellos que, dobles, están adornados por un 'sombrero'; aquellos que (con la punta negra, el medio rojo y la raíz blanca) tienen una 'montura'; aquellos, en fin, que están provistos de una cresta de gallon (Leiris 1996: 169. 6.VIII.31).
} 
validez del empeño ${ }^{8}$. Esta contradicción entre la esperada espontaneidad de un dietario y su proyectada publicación, ¿lo convierte -como quiere Clifford (1995: 205) - en "una doble lectura imposible", en un "libro ilegiblen? No lo creo; por el contrario, la doblez es característica inevitable de la práctica etnográfica y es la experiencia misma de tal condición lo que se torna el objeto mismo del libro.

La argumentación con la que el autor juega es que la subjetividad extrema lleva a la objetividad total; es decir, que al exponer las condiciones personales de la investigación se permitía que los resultados de ésta pudiesen ser expurgados del grado de refracción que inevitablemente cargaría ${ }^{9}$. Desde ese punto de vista, sostiene en un proyecto de prefacio integrado en el diario (Leiris 1996: 395. 4.IV.32), lo ideal sería un registro que abarcase también los avatares orgánicos "cómo se ha comido, cómo se ha hecho el amor, cómo se ha meado, [...] exponiendo el coeficiente personal, a fin de permitir el cálculo del error, lo que es la mejor garantía posible de objetividad. Ingenua, sin duda, esa voluntad de poner esta "etnografía de la etnografía" (Izard 1983: 138) al servicio de una objetividad científica cuya prosecución llega a fascinarle ("comienzo a entrever lo que hay de apasionante en la investigación científica. Ir de pieza de convicción en pieza de convicción, de enigma en enigma, persiguiendo la verdad como una pista" [Leiris 1996: 152. 16.VII.31]).

Ingenua, pero en el fondo acertada, en una dimensión de mucho más alcance del que Leiris pretendía; más allá de las refracciones idiosincrásicas

\footnotetext{
8 Tenemos también cartas: de Leiris a su mujer, esbozando la estrategia para la publicación del diario (el deseo de que se publique en Gallimard - por intermedio de Malraux y Paulham - y de evadir el contrato firmado con otra editorial por el que el poeta se había comprometido a entregar una serie de obras indeterminadas); una de Schaeffner (1991 [1932]) a Leiris, poco después de que se hubiesen separado cerca de la frontera etíope, en la que se vierten sus impresiones sobre la lectura de varios centenares de páginas del diario: éste debe ser publicado sin alteración alguna (idea que Leiris tenía desde un comienzo, aunque sí haya algunas pequeñas modificaciones, cf. nota 31).

9 Argumento similar al empleado años más tarde por Condominas (1991 [1965]: 40): “[...] he creído provechoso desmontar mis propios mecanismos y describir las etapas que me fueron conduciendo a la experiencia que debo escribir, con el fin de poder aportar así a aquellos que utilizarán los resultados de mis investigaciones los medios de determinar exactamente la parte de elementos subjetivos que se han deslizado, de detectar los puntos débiles y de tener una idea precisa del margen de error con el que se puede encontrar". Algo parecido también está en De Martino (1999 [1961]: 18): “[...] la objetividad del etnógrafo no consiste en fingir desde el principio de su trabajo que está por encima de las pasiones, con el riesgo de caer en pasiones mediocres y vulgares, y dejar que influyan inconscientemente en el discurso etnográfico, como gusanos pululando dentro de un sepulcro de mármol; se basa, por el contrario, en el propósito de unir su viaje al reconocimiento explícito de una pasión actual [...].
} 
que cada investigador en particular pueda hacer sufrir a sus observaciones, hay una refracción genérica. L'Afrique... no habla sólo o no habla tanto de una práctica etnográfica concreta; habla de cualquier etnografía: ese es el centro de su validez.

El autor debía de sentir el ojo público mirando por encima de su hombro a cada anotación que efectuaba. No se trata, pues, de un diario al estilo del de Malinowski (1989 [1966]), ya que a éste no se le había pasado por la cabeza mandarlo a imprenta; tampoco de ajustes de cuentas con la memoria más tardíos como el de Lévi-Strauss (1955) ${ }^{10}$, el de Condominas (1991 [1975]) o el de Descola (1993), o más cercanos a la experiencia narrada como The savage and the innocent de Maybury-Lewis (1988), el pequeño libro de Rabinow (1992) sobre su trabajo de campo en Marruecos o los éxitos de ventas de Barley. Es un inmediato presente, mediado por un proyecto.

En términos estilísticos, ese proyecto establece una tensión entre un cuidado muy particular de la escritura y su recurrente repugnancia a aliteralizar" el texto. Repugnancia que no sólo se refiere a la literatura, sino que es de un porte mucho más vasto y que se había convertido en el resorte que le había hecho abandonar París para sumarse a la aventura africana de Griaule. Es el vértigo de muchos intelectuales, de los intelectuales franceses de la época más que nada, que les hace anhelar un cambio de piel con los hombres de acción y renunciar a la palabra: "Lo primero es ser ardiente. Y yo lo soy [...]. Basta de poemas, basta de palabras, sólo acontecimientos. Saber fustigar a un asno o a cualquier otra bestia de carga. Responder de una tarea ante quienquiera que sea y por lo que sea. En otros tiempos, quizás hubiera sido yo un buen mercenario" (Leiris 1996: 470. carta del 30.V.32). El silencio de su admirado Rimbaud, que "había mandado todo a paseo para irse a Abisinia", era un modelo tentador.

\footnotetext{
${ }^{10}$ La comparación entre Lévi-Strauss y Leiris parece obligatoria. Cercanos en edad (de 1908 el primero, el segundo de 1901), vinculados ambos (directamente uno, el otro no) a la enseñanza de Mauss, en un círculo cultural no muy lejano, los dos en los trópicos casi al mismo tiempo (uno de los nombres pensados en un comienzo por Leiris para L'Afrique... fue "El paseante de Cáncer" —había otra ocurrencia: "La sombra de la aventuran-), y, al mismo tiempo, tan en las antípodas uno del otro. ¿Alguien imagina a Lévi-Strauss - que ni siquiera menciona a su mujer Dina (antropóloga como él y con mayor inserción que él en la vida cultural brasileña) en Tristes tropiques- mostrando, como sí hace una y otra vez Leiris, aspectos poco halagüeños de su vida sexual? Sobre la comparación entre L'Afrique... y Tristes tropiques, ver Peixoto (1992); sobre la cuidadosa construcción de la carrera de Lévi-Strauss en su estancia brasileña, Peixoto (1998); también, ver la entusiasmada reseña de Tristes tropiques hecha por Leiris (1969 [1956]). Otro punto de semejanza entre ambos; también la publicación de estas memorias disgustó a Rivet (Lévi-Strauss y Eribon 1990: 87).
} 
Pero Leiris no calla; muy por el contrario, escribe, escribe, escribe. Escritura ésta que se establece en distintos planos, lo que Mercier (1994: 30 , n. 18) llama "escritura en estratos": informes, fichas etnográficas, traducción de los textos recogidos con la ayuda de colaboradores nativos, diario, cartas, y, más tarde, artículos y libros. Algunos de los textos producidos, como los informes y las fichas, materia prima de elaboraciones más ambiciosas o cumplimiento de su papel de archivero de la Misión, son mantenidos a distancia de la redacción del diario, salvo en el momento en que, ya lo veremos, se produce un cortocircuito en la escritura y en la vida de Leiris.

Las cartas a su mujer Zette - trechos de las cuales ocupan los márgenes del cuerpo del texto en la edición de Jamin - contienen con frecuencia formulaciones más lúcidas y logradas que las propias anotaciones del diario: ese interlocutor privilegiado, ese lector único, obligaba a la elaboración de un saber a transmitir, del que el diario podía permitirse carecer. Razón por la cual, a la hora de volcar en este texto que escribo la experiencia de Leiris, mi continua tentación, tentación en la que por cierto he caído, ha sido acudir a esas cartas; no necesito, pues, dar ejemplos adicionales.

Los textos definitivos - en lo esencial La langue secrète des Dogons de Sanga y La possession et ses aspects théatraux chez les éthiopiens de Gondar-, muy posteriores al trabajo de campo, se diferencian por completo del estilo y contenido de L'Afrique... La labor propiamente etnográfica, en estos textos, se abstrae de la experiencia que los hizo posible al igual que, en el diario, el trabajo etnográfico quedaba de lado ("cuando redactaba esas notas cotidianas que constituyen la materia de L'Afrique Fantôme, no pensaba para nada en hacer etnografía. Era al margen, verdaderamente al margen de mi trabajo etnográfico" [Price y Jamin 1988: 45]); esa experiencia había sido ya lo bastante elaborada como para necesitar volver sobre ella.

Suerte de bildungroman, es el diario de un viaje espacial y moral, pero no cae en el peligro que preocupa al autor, el de ser un "libro de viajes" ("iNo es verdad que escribir un libro de viaje es una apuesta absurda por donde se la mire?» [Leiris 1996: 379. 18.III.32); en modo alguno su efecto es "infundir en los diletantes sensaciones turísticas", a diferencia de Griaule, a quien los trabajadores de hostelería de Sanga deben hoy su puesto. Estamos, en ese sentido, en la misma veta que el "odio a los viajes y a los exploradores" de Lévi-Strauss.

L'Afrique... está dividida por el autor en dos partes; la primera abarca desde la partida de Burdeos hasta la llegada a la frontera etíope; la segunda, desde ese momento hasta el día anterior a la llegada en barco a 
Marsella. Una y otra parte tienen sus núcleos: el trabajo en Sanga con los dogon, la primera; la segunda, la mucho más prolongada estancia en la etíope Gondar y el trabajo sobre el culto de posesión de los zar.

\section{EL ETNÓGRAFO, FANTASMA}

La llegada al país dogon resulta para Leiris mucho más emocionante que todo lo visto y vivido las semanas anteriores. Su primera anotación ( FFormidable religiosidad. Lo sagrado inunda todos los rincones. Todo parece sabio y grave. Imagen clásica de Asia». Leiris 1996: 213. 29.IX.31) marca el embeleso bajo el que vivirá esta experiencia y con el que encarará el trabajo sobre la lengua ritual de la sociedad masculina de las máscaras, el sigi so, al que me referiré con algún detenimiento más adelante. África aún no es un fantasma; mantiene y cumple las promesas que han atraído a los expedicionarios. Estamos en pleno espíritu Griaule, en pleno esplendor edénico:

Aquí la religión tiene un sentido, ya que se le pide algo preciso. El amor tiene un sentido porque está oculto. La belleza lo tiene porque es involuntaria. La estupidez no existe ya que no se habla de inteligencia. Nada se hace mal, nada falta, porque no se habla de eficacia. No hay decrepitud, ni nacimiento, ya que todo está articulado en un ciclo continuo (Leiris 1996: 242. carta del 23.X.31).

En contradicción con una pureza tal, con una desnudez tal ${ }^{11}$, todo intento de tomar de los nativos -la labor etnográfica - se le muestra como una intromisión violenta:

Los métodos empleados por la investigación se asemejan mucho más a interrogatorios de un juez de instrucción ${ }^{12}$ que a conversaciones en un plano amistoso y los métodos de recolección de objetos son, el noventa por ciento de las veces,

${ }^{11}$ Frente a la simplicidad de la desnudez adánica, el caos de nuestros atuendos: "Admirable limpieza de las gentes desnudas. Absoluta corrección de su porte, frente al cual todo lo que es vestido parece cursi o golfo. ¿Qué horrible embrollo, nuestras civilizaciones!" (Leiris 1996: 370. 10.III.32).

${ }^{12}$ Esta identificación entre el trabajo etnográfico y el judicial, era muy cara a Griaule. En otra anotación Leiris vuelve sobre el tema, en forma aún más decepcionada: "Yo que contaba volver de África con el aspecto de uno de esos bellos corsarios deteriorados. La vida que aquí llevamos no podría ser más chata y burguesa. El trabajo, en lo esencial no difiere de un trabajo de fábrica, de gabinete o de despacho. ¿Por qué la investigación etnográfica me hace pensar tan a menudo en un interrogatorio policial?" (Leiris 1996: 391. 31.III.32). En una carta del día anterior, definía el trabajo etnográfico como una empresa burocrática. 
métodos de compra forzada por no decir requisaciones (Leiris 1996: 204. carta del 19.IX.31).

Leiris no habla en vano; en el diario registra varios episodios en los que Griaule y él roban objetos sagrados dogon ${ }^{13}$. El robo, sin embargo, es preferible a la compra ya que ésta envilece a los nativos: "hay objetos sublimes que sería mil veces más innoble comprar que robar" (Leiris 1996: 266. carta del 13.XI.31). No obstante, estas anotaciones y cartas de Leiris no son una crítica moral a tales conductas; es como si tan sólo registrase la realidad inevitable de la acción etnográfica, aunque, además, el propio acto del latrocinio le moviese su amor por la transgresión (ame dejan sin remordimientos, porque no hay otro medio de tener esos objetos y el mismo sacrilegio es un elemento bastante grandioson. Ibidem). De todas maneras, le queda claro que la relación con los nativos es un círculo vicioso en el que éstos sólo pueden perder: "saqueamos a los negros bajo el pretexto de enseñar a la gente a conocerlos y amarlos, es decir, a formar otros etnógrafos que irán ellos también a amarlos y saquearlos" (Ibidem). El pillaje no fue sólo del tipo de objetos tras los que han llegado a sus tierras los etnógrafos; el conocimiento que éstos llegarán a producir tiene como efecto el mantenimiento de la sujeción de los nativos y su exacción por las autoridades coloniales:

Soporto cada vez menos la idea de la colonización ${ }^{14}$. Cobrar impuestos, esa es la gran preocupación. Pacificación, asistencia médica, sólo tienen una finalidad: engatusar a la gente para que se convenzan y paguen los impuestos. Incursiones a veces sangrientas, con qué finalidad: hacer pagar los impuestos. Estudios etnográficos, con qué finalidad: ser capaces de llevar una política más hábil que será más capaz de hacer pagar los impuestos ${ }^{15}$ (Leiris 1996: 336. 26.I.32).

\footnotetext{
${ }^{13}$ Los dogon siguieron siendo objeto de la cleptomanía etnográfica con la misión Paulme-Lifchitz. Paulme (Lifchitz y Paulme 1987 [1935]: 49), en carta a Leiris (19.III.35): "Hemos robado, con el corazón en la boca, estatuillas en la caverna de Bongo, bajo la mirada de los habitantes".

${ }^{14}$ Lo colonial es el orden francés en provincias más lejanas; la diferencia es que no hay ocultamiento: “Un viaje a las colonias es una lección inolvidable: se ve todo de cerca, sin ninguna máscara, sin ningún decorado. Nada tiene que ver con las sensaciones exóticas que es fácil imaginar. Es abrupto como la vida" (Leiris 1996: 211. carta del 26.IX.31).

${ }^{15}$ Leiris no sospechaba que fuesen a ser ellos mismos, los etnógrafos-marchantes, quienes pusiesen en manos de los nativos el dinero con el que éstos pagarían los impuestos, tal como décadas más tarde contaría Paulme a Annie Dupuis, como explicación de por qué ella y su compañera Lifchitz recolectaron piezas para el Museo del Hombre cuando en principio no lo habían programado: "[...] para pagar los impuestos en febrero, tenían necesidad de dinero francés, ya que en todos los mercados las
} 
De la estancia en Sanga y el trabajo de campo sobre la lengua secreta de la cofradía masculina de las máscaras, además de los breves artículos de Minotaure, tenemos, por un lado, el registro diario en L'Afrique... $\mathrm{y}$, por el otro, un resumen en la Introduction a La langue secrète des Dogons de Sanga. La obligada coherencia expositiva de éste se aparta de la inmediatez de lo cotidiano de aquél, pero entre una fuente y otra la figura se completa. Veámosla en sus líneas generales.

El cometido primero que había dado Griaule a Leiris ${ }^{16}$, además del de "secretario-archivero" de la Misión con el que había salido de Francia, fue la recopilación de textos en esta lengua, su compleja traducción (del sigi so al dogon normal y de éste al francés), así como el estudio de las condiciones y circunstancias de su empleo. A tal tarea dedicó en el campo menos de cincuenta días - del 29.IX.31 al 19.XI.31-, y en el gabinete más de quince años cuando por fin publicó su libro de cerca de 600 páginas ${ }^{17}$.

Al día siguiente de la llegada de la Misión a Sanga, Leiris comenzó un trabajo sobre la cofradía de máscaras de la región. Su primer informante, Ambara Dolo, era un hombre más o menos de su misma edad, un ex alumno de la escuela preparatoria del poblado, con un dominio del francés bastante aceptable. Su inestabilidad psicológica y su carácter fantasioso (que no impedían, sino - me imagino- favorecían la buena relación con Leiris) no lo hacían el informante soñado para una investigación profunda sobre las cofradías de las máscaras", a pesar de haber él mismo participado en ellas durante años ${ }^{18}$. Esta dificultad pronto se

transacciones se hacían en cauríes; entonces, nos traían objetos para tener dinero para pagar los impuestos" (Lifchitz y Paulme 1987: 52, n. 22).

${ }^{16}$ De hecho, el primer tema de trabajo pensado para Leiris eran las sociedades infantiles en Senegal y Sudán.

${ }^{17}$ Leiris presentó a L'École Pratique des Hautes Études una primera versión del texto en 1938 que fue muy criticada por Louis Massignon, a quien correspondía su evaluación. "Tenía que rehacerlo todo", decía al respecto Leiris cincuenta años más tarde (Price y Jamin 1988: 45). De todas maneras, le fue concedido el grado académico al que Leiris optaba (Diploma de la École Pratique des Hautes Études. Leiris 1991 [1967]: 6]; en este informe, presentado con su candidatura al puesto de director de investigación del CNRS, se encuentra un breve resumen de su trabajo). También en 1938 hizo un breve esbozo de la cuestión en "La langue de la société des hommes chez les dogons de Sanga", Anthropologie, n. ${ }^{\circ} 48$.

${ }^{18}$ Ambara también fue informante de Denise Paulme durante su estancia en Sanga en 1935; le debemos este sensible retrato: «[...] la piel de un tono bastante claro, la nariz fina, el mentón recto, la barba corta y rizada, Ambara no recuerda en nada el tipo habitual del 'negro'. Agreguemos que es el único Dogon que hayamos visto llevar en todas las circunstancias dos pequeñas argollas en las orejas, de cobre entor- 
resolvió. Tras diez días de trabajo conjunto, aparecía un nuevo personaje que iba a convertirse en una figura central, no sólo de esta investigación de Leiris, sino de otras realizadas en las futuras estancias de Griaule entre los dogon, un anciano - Ambibè Babadyi-que, enterado de la llegada de un grupo de franceses que pagaban a sus informantes, vino a ofrecer sus servicios. Resuelta la cuestión pecuniaria (significativa, a mi entender, y sobre la que volveré más tarde), comenzaba su colaboración.

Comenzaba también un pulso continuo de Leiris con su informante que - según él- le mentía, le ocultaba datos esenciales, no acudía a las citas de trabajo: "Ambibè Babadyi es un viejo canalla. [...] me ha mentido, dándome un montón de detalles pero omitiendo a propósito las cosas esenciales. Por poco, lo estrangularía" (Leiris 1996: 244. 30.X.31). Y también: "[...] mi historia con el viejo Ambibè Babadyi ha sido una gran decepción, ya que [...] es siempre penoso darse cuenta brutalmente de que uno ha sido engañado" (Leiris 1996: 256. carta del 7.XI.31).

Este primer contacto cara a cara con nativos, este bautismo de fuego, le mostraba, tomase o no conciencia de ello, que el nativo tiene una propia lógica en la que tratará de absorber al etnógrafo y que en esto radica la esencial igualdad humana de uno y otro; "Leiris nos enseña esto" - escribe Séité (1999: 40) hablando de otra cuestión e invirtiendo la frase de Rimbaud- "que el Otro es un Yo" ${ }^{19}$. Aquél usará a éste —cuando pue$\mathrm{da}$, como pueda - para sus propios fines, de igual manera que el etnógrafo lo usa a él para los elevados fines de la Ciencia.

\footnotetext{
chado, que permanecen en nuestra memoria inseparables de su fisonomía. De estatura privilegiada, hombros anchos y cintura delgada, llevaba siempre, no sin elegancia, hasta el fin de nuestra estancia, una levita verdosa cuyos faldones desgastados golpeaban sus nerviosas pantorrillas. [Tras su estancia en Bamako] su naturaleza indolente le permitió readaptarse con facilidad asombrosa a la vida de la aldea, donde sus aventuras le otorgan un prestigio envidiado. Su estancia en una ciudad europea y su conocimiento del francés le han dado una alta opinión de sí mismo que se traduce [...] por una sonrisa desdeñosa [...], una articulación lánguida y un tono de voz ligeramente gangoso" (Paulme 1940: 57). La tradición Griaule lo convertiría décadas más tarde en un personaje acorde con sus propias aspiraciones sublimes: "El aristócrata intelectual, uno de los espíritus más finos que hemos encontrado entre los Dogon, nadie lo igualaba para esclarecer una cuestión enmarañada y expresarla en imágenes cautivantes, para dominar los problemas, captar las oposiciones y las relaciones, citar una anécdota o un proverbio corriente que ilustran su pensamiento y lo tornan vivo" (Calame-Griaule 1987: 13).

${ }^{19}$ En un contexto por completo diferente, y, seguramente, sin tener a Leiris ni por asomo cerca de sus preocupaciones, dice Comelles (1992: 152): «[...] porque los locos, los maghrebíes, los beti o los gambianos no son sino una manera distinta de ser nosotros".
} 
Una anécdota banal lo muestra a las claras: Ambara, pícaro, holgazán, fantasioso, borrachín, se aprovecha de la ingenuidad de Leiris; tras salir de una reunión familiar, pretextando vergüenza ritual ante su suegro:

me pidió que volviese a la casa de la que habíamos salido, para que diese a su mujer un boubou que debe remendar para alguien de otro barrio, misión que cumplo, siguiendo los consejos de Ambara, depositando la prenda entre las manos de la muchacha y apuntando repetidas veces con el dedo índice de la mano derecha en dirección al barrio donde vive el interesado. [...]. Curiosa comedia que no engaña a nadie, salvo a sí mismos, como la ignorancia que todos fingen, durante la danza de las máscaras, sobre la identidad de los disfrazados (Leiris 1996: 224225. 4.X.31).

El engañado era, sin embargo, Leiris, que a los pocos días se enteraba por uno de los compañeros de la misión de que no eran las mujeres, sino los hombres, los encargados de la costura entre los dogon. Ambara pretendía obtener ese servicio de su mujer, para lo cual se escudaba detrás del francés y su pantomima ridícula, al mismo tiempo que evitaba que su pereza escandalizase a su suegro.

Pero la lección primera que sacaba Leiris de su contacto con los dogon no ponía tanto en juego al "otro", como al "sí-mismo" en contacto con él: el etnólogo es un actor, un comediante, y no puede no serlo. En la base de su oficio está la actuación de sí mismo; él y sus compañeros son como "gente de circo que se desplaza todo el tiempo pero para dar siempre el mismo espectáculo" (Leiris 1996: 138. 4.VII.31). Circo eficaz, ya que, al margen de la voluntad de sus integrantes, divierte a su público:

Qué poderosa distracción deben representar los turistas para estas gentes. Debemos ser, en efecto, animales super cómicos con nuestro atavío extravagante, tan insólito bajo este cielo, en esta hierba, sobre esta tierra roja, en medio de esta vegetación (Leiris 1996: 366. 4.III.32).

El trabajo etnográfico es descubierto por Leiris como representación, lo que le resulta sinónimo de "inautenticidad". Esto, que es verdad para cualquier papel social, lo es en una forma potenciada para el antropólogo en el campo, más aún en el caso de la Misión Dakar-Yibuti, por su número de integrantes, la metodología empleada, la filosofía y la personalidad de Griaule, su carácter de "safari etnográfico" (Jamin dixit). En un primer momento, esa actuación parece a Leiris una pérdida, una artificiosidad que suplanta una relación más auténtica: la representación ahoga la presencia. Tras registrar un encuentro con familiares de su informante Ambara, lleno de ceremoniosas fórmulas de afecto, anota: 
Qué siniestra comedia hemos representado estos viejos dogons y yo. Hipócrita europeo, todo azúcar y miel, hipócrita dogon tan rastrero porque era el más débil, no es la bebida fermentada lo que nos acercará más. El único lazo que hay entre nosotros es una falsedad común (Leiris 1996: 225. 4.X.31) ${ }^{20}$.

La representación, además, no se efectúa sólo ante los ojos de los nativos; hay otra también inevitable, ante ellos mismos, como hombres que deben convivir día a día, con la vida cuartelera quizás como único modelo de conducta. En un momento en el que otros miembros se separan por unos días de la Misión, Leiris se alegra de que por un tiempo se haya acabado el

tumulto militar, bromas de almanaque, charlas sin sentido, vociferaciones contra los señores boys [ $=$ porteadores y criados nativos], tristes exteriorizaciones de hombres que un inevitable espíritu de cuerpo, cuando son más numerosos, doblega bajo su férula de burlona vulgaridad (Leiris 1996: 237. 21.X.31)

En forma concomitante, otra desencantada lección que Leiris recibía a poco de comenzar el real trabajo de la Misión era que la labor etnográfica inhabilita para la pura contemplación; o se trabaja o se disfruta:

Todo es visto en función del trabajo en curso y cualquier espectáculo será ante todo pretexto de notas y fotografías. Es lo que ha ocurrido durante todas estas fiestas de funerales Ise trata de los funerales de "El cazador del 20 de octubre", clave en la formulación de la metodología de Griaulel que no hemos mirado, si se entiende por "mirar" contemplar de una manera estética y desinteresada (Leiris 1996: 244. carta del 27.X.31) ${ }^{21}$.

\section{EL OTRO, FANTASMA}

La utopía de la espontaneidad, de la inmediatez de las relaciones humanas y de la creación, fue una de las grandes ilusiones del surrealismo ${ }^{22}$; la escritura automática de la que se valió como instrumento privile-

${ }^{20}$ Derive (1998: 22) entiende que la hipocresía deriva de la situación colonial. No lo veo así; se trata, a mi entender, de una distancia protocolaria impuesta por la alteridad, no por la jerarquía o la dominación.

${ }^{21}$ Y también, refiriéndose a los objetos que la misión estaba recolectando: «Saber que apenas los verás corta mi alegría; cuando los veas estarán en París, en una caja o una vitrina de museo. Habrán perdido toda su frescura y habrán caído al nivel de abyectos objetos de colección" (Leiris 1996: 256, carta del 7.XI.31).

${ }^{22}$ Era uuna poética [...] que soportaba mal que un saber se interpusiese entre su mirada y el objeto" (Jamin 1994: 16). 
giado de producción poética así lo señala. El África de la imaginación parisina - esas desnudeces, esos primitivismos- hace que Leiris desembarque en el continente negro con la esperanza en el corazón de que lo otro sea en verdad lo auténtico y que uno, en ese contacto, pueda purificarse de la inautenticidad occidental. Ya en Sanga, lo hemos visto, tal esperanza quedaba maltrecha. Su experiencia en Gondar sería más radical, más dolorosa, más iluminadora.

La primera reacción de Leiris al entrar en contacto, poco después de llegar a Etiopía, con el culto de posesión de los espíritus zar. "Preferiría ser poseído que estudiar a los poseídos, conocer carnalmente a una 'zarina' que conocer científicamente sus pormenores. El conocimiento científico jamás será para mí más que un apaño" (Leiris 1996: 560. 23.VII.32). Pero es aquí, en Etiopía, entre los poseídos de Gondar, donde se jugará el gran viraje entre la inmediatez del deseo y la mediatización de la ciencia.

Ser etnólogo es, va a ser para Leiris, renunciar al afán de llegar al otro lado del espejo para allí quedarse, que, antes de su arribo a Gondar, podía registrar en su diario de una manera banal, digna de un turista ("Quedarse aquí. Ya no hacer nada. Instalarse en la montaña. Tomar aquí mujer y fundar un hogar. Deseo utópico que me dan estas gentes y sus presentes agrestes" [Leiris 1996: 321. 7.I.32.]).

Ser etnólogo es, va a ser para Leiris, dejar de ser surrealista (pero no, por cierto, dejar de ser poeta). En medio de la crisis que en las páginas siguientes voy a abordar, escribe: "Creo que he terminado con el surrealismo... Que todo eso me pueda parecer falso y desagradable es repulsivo" (Leiris 1996: 790. carta 28.XI.32). Ser etnólogo va a ser, para Leiris, asumir que la autenticidad que le cabe -que nos cabe- es la inautenticidad.

Hubo un episodio que desencadenó y precipitó este salto: su pasión por Emawayish, hija de Malkam Ayyahou, la sacerdotisa que le permitió adentrarse en el conocimiento del culto zar. Entonces sufrirá una enorme tensión entre el deseo de perderse $\multimap$ o encontrarse- allí, fuera de sí, en el reino de lo maravilloso, y la (in)evitable conciencia de su imposibilidad de consentírselo.

En esta pasión - de un hombre de treinta años que, si se me permite mencionarlo, hacía casi dos que no tenía relaciones sexuales ${ }^{23}$ ni se

23 “Soy casto desde hace casi dos años. Algunos dirán que soy impotente, dirán que no tengo huevos. Abstrayendo todas las razones sentimentales que pueden motivar esa castidad, hay algo evidente: no me gusta follar en sociedad. Soy lo bastante misántropo como para querer, viviendo en grupo, quedar al margen. Para llegar a una separación tal, negarse en cuanto macho, ¿no es uno de los medios más seguros" (Leiris 1996: 797. 1.XII.32). 
masturbaba - interviene una cuestión densa y compleja que sin duda es clave para comprender lo sucedido, la relación de Leiris con las mujeres y con el sexo, temas que, sobre todo en la etapa etíope, aparecen una y otra vez en el diario. Temas que, por otro lado, junto a otros problemas - el alcoholismo y la falta de concentración en el trabajo-, lo habían llevado al diván de Adrien Borel (Lejeune 1986: 171); el alta dada por este psicoanalista fue uno de los resortes que llevó a que Leiris aceptase la invitación de Griaule para sumarse a la Misión.

Los surrealistas quisieron ser transgresores en todos los planos, salvo en uno, el sexual. Orgullosos heterosexuales (su antipatía por Genêt, según Sartre, provendría del escandaloso homosexualismo estilo vieille tante de éste), fueron también monógamos virtuosos. Sus mujeres semejan las damas de los trovadores provenzales, objeto, como éstas, de hermosos poemas de amor, tan emocionantes como Union libre de Breton o J'ai tant rêvé de toi de Desnos. Tanta devoción lírica puede hacer sospechar cierto descarnamiento en el cuerpo a cuerpo; en el caso de Leiris tal sospecha no está desencaminada. Las relaciones sexuales se le daban muy mal; es lo que llama su "malthusianismo" (mi "actitud dramática frente al coito" ${ }^{24}$ [Leiris 1996: 839. 28.XII.32]) que lo llevaba a que sus cópulas, cuando accedía a ellas, con frecuencia no fuesen completas. Pero esta mutilación sexual no es más que una parte de una mutilación mayor, la que lo convierte en una especie de "paria sentimental". La reserva a su propio deseo por un cuerpo de mujer no es más que el caso más doloroso de sus reservas de estar con otros: "Lo que me hace retraer y rezongar del coito, es el miedo al contacto humano, como si el goce estuviese medido no sólo por ese contacto, sino por ese propio miedo" (Leiris 1996: 830. 23.XII.32).

\footnotetext{
${ }^{24}$ Dramatismo que llegaba a tener una vertiente mágica: "Siempre he visto más o menos al coito como un acto mágico, he esperado de ciertas mujeres lo que se puede esperar de los oráculos, he tratado a las prostitutas como pitonisas" (Leiris 1996: 578. 8.VIII.32). Pero esto lo escribe después de su introducción en el mundo $z a r$, con la enorme sexualización que desde el primer momento Leiris vive allí. Sobre su actitud frente al sexo y a la reproducción: "Sexualmente no soy, creo, un anormal - simplemente más bien un hombre frío- pero desde hace mucho tiempo tengo la tendencia de tenerme por casi impotente. [...] Me sería imposible hacer el amor si, al llevar a cabo este acto, lo considerase de otra manera que como estéril y sin nada en común con el instinto humano de fecundar. Llego a pensar que el amor y la muerte -engendrar y deshacerse, que llevan a lo mismo- son para mí cosas tan próximas que toda idea de alegría carnal no me toca más que acompañada de un terror supersticioso, como si los gestos del amor, al mismo tiempo que llevan mi vida a su punto más intenso, sólo debieran de traerme desgracias" (Leiris 1999 [1939]: 25-27).
} 
La tan larga ausencia de Zette quizás haya sido para Leiris un obscuro beneficio adicional del viaje, viaje que en algún momento sentía como haciéndose por el cuerpo de la amada distante: "Estar lejos de una mujer y vivir en la ausente, que está disuelta y como desvanecida, ya no existe en cuanto cuerpo separado, sino que se ha convertido en el espacio, la fantasmática carcasa a través de la cual uno se desplazan (Leiris 1996: 298. 18.XII.31). Cogez (1999), que curiosamente no recurre a este texto que viene a abonar su análisis, encara la relación de Leiris con África como una vía para que éste resolviera sus complicadas relaciones con las mujeres: "Lograr las gracias del género femenino en su conjunto, es ese quizás el sueño africano de Michel Leiris, crudamente resumido". Las mujeres -su propia mujer Zette, ante todo- son fantasmas, tanto como lo es esta África cuya realidad se le escapa de entre los dedos ${ }^{25}$.

Vayamos a los hechos, o, mejor, a la narración de los hechos. Quien introdujo a Leiris en el mundo de los zar fue Abba (padre) Jerôme Gabra Madhin, un sacerdote católico expulsado del magisterio por la cúpula eclesiástica, nacido en una región etíope que Italia había incorporado a su dominio eritreo y muerto en París medio siglo después de estos acontecimientos, con más de 100 años. Este curiosísimo personaje, a quien Griaule conoció por intermedio de su maestro Marcel Cohen, había desempeñado diversos encargos diplomáticos por parte de su gobierno y fue enviado por el nuevo emperador para colaborar con la Misión.

Leiris tuvo relaciones muy ambivalentes con este hombre. Aun antes de conocerlo, en la primera anotación del diario donde aparece su nombre (Leiris 1996: 548. 14.VII.32), la reacción espontánea era de sospecha: "Abba Jerôme pertenece al Ministerio de Asuntos Extranjeros etíope. Es un enemigo de los italianos. ¿Por qué, de repente, viene aquí? ¿Qué hay que espiar? ¿Nosotros, nuestra compra de manuscritos o la actividad de los italianos?. Los diversos retratos que luego nos presenta están teñidos de una cierta ridiculización condescendiente del intelectual de un país, Etiopía, que ve entre el medioevo y la opereta, y del que, después de todo, siempre habla en su diario con suma altanería.

Más tarde, habría irritaciones agudas, malos modos, celos, y, por fin, ataque de rabia cuando Abba Jerôme desertase de la Misión en la fron-

\footnotetext{
${ }^{25}$ Qué cerca estamos del poema de Desnos que mencioné líneas atrás, que termina así: "tanto soñé contigo, tanto caminé, hablé, me tendí al lado de tu fantasma que ya no me resta sino ser fantasma entre los fantasmas, y cien veces más sombra que la sombra que siempre pasea alegremente por el cuadrante solar de tu vidan (traducción de Aldo Pellegrini). Una especie de pequeño resumen de este poema fue encontrada sobre el cadáver del autor, muerto poco después de ser liberado de un campo de concentración nazi.
} 
tera con territorio italiano ${ }^{26}$. Pero, al mismo tiempo, Leiris no dejaba de reconocer su capacidad: «es un hombre que tiene instinto poético de la información, es decir, el sentido del detalle en apariencia insignificante pero que sitúa todo y da al documento su sello de verdad. Aunque a veces me irrita, en el fondo me entiendo muy bien con él" (Leiris 1996: 573. 5.VIII.32). De hecho, casi todo el trabajo de Leiris en Gondar dependió de la intermediación de Abba Jerôme: por la presentación a Malkam Ayyahou, por su papel de intérprete, por la recopilación de poemas y cantos entonados en las ceremonias y fuera de ellas, por la redacción de gran cantidad de descripciones de rituales, por el servicio constante y generoso a Leiris, quien, por otro lado, tenía veinte años menos que él.

Abba Jerôme había llegado a casa de Malkam Ayyahou de una manera tan casual como afortunada. Tras su arribo a Gondar, no fue recibido por quien se suponía tener que albergarlo; en medio de la calle, bajo la lluvia, se encontró con un amigo de la capital que lo llevó a casa de la zarina para que ésta le alquilase un cuarto. La noche posterior a su llegada, tuvo allí lugar una sesión de posesión que contó al día siguiente en el campamento de la Misión. Leiris anotó entonces un incidente que mostraba la liberalidad sexual del culto y que, sin dudas, encendió su imaginación:

Uno de los servidores de Abba Jerôme que asistía a la sesión, quiso tomar - sobreexcitado- a una de las "señoritas" ${ }^{27}$; la jefa, indignada, le habría dicho que un deseo tal sólo podía llevarse a cabo afuera. Sin embargo, le habría permitido hacer su elección en el interior (Leiris 1996: 554. 20.VII.32)

Unos días más tarde, Leiris, que hasta entonces había trabajado sin mayor entusiasmo con un agente del zar indicado por Griaule - - el dabtara (sacerdote) cojon - usando los servicios de intérprete de uno de los ayudantes nativos de la Misión, comienza su colaboración con Abba Jerôme ya instalado en el campamento. Primera tarea conjunta: traducir y comentar las notas tomadas por el etíope en casa de Malkam Ayyahou ( $m$ me apasiono un poco, ya que despierta mi enfermizo gusto por lo estrambótico" [Leiris 1996: 560. 24.VII.32]).

${ }^{26}$ Los italianos, por cierto, querían la cabeza de Abba Jerôme, uno de cuyos cometidos diplomáticos había sido conseguir armas para el ejército etíope, armas que serían infructuosamente usadas contra los italianos poco después. Cincuenta años más tarde, Leiris (1996a [1983]) reconocería la absoluta injusticia de su actitud en un hermoso artículo donde le daba el apelativo Berhanê ( $M i$ luz", el que explica, el que esclarece) con que Malkam Ayyahou acostumbraba a dirigirse a él.

${ }^{27}$ Una de las mujeres poseídas. 
Desde el primer momento, además, Griaule insiste en que Abba Jerôme medie ante la zarina y obtenga la autorización para visitarla y estudiar allí el culto ${ }^{28}$. Abba Jerôme obtiene la autorización, cosa nada difícil, por cierto. Pero su participación no termina aquí; muy por el contrario, aquí comienza. No hay prácticamente un momento en que Leiris esté a solas con quien quiera que sea del grupo de poseídas dirigido por "la patrona de los zar. Las conversaciones entre él y Malkam Ayyahou, Emawayish, Dinqié - una subordinada de Malkam Ayyahou con quien Leiris trabajaría más tarde-, los hijos de Emawayish, etc., jamás fueron diālogos: siempre tuvieron a ese tercer hombre como puente que unía tanto cuanto separaba. Por más que injusta, no es de extrañar, pues, la irritación que tantas veces sintiera Leiris a su respecto.

Leiris visita por primera vez a Malkam Ayyahou ("conjuga la alcahueta, el bufón y la pitonisan) el 28 de julio, pero no conocería a Emawayish ("princesa con rostro de ceran [Leiris 1996: 572. 2.VIII.32]) hasta unos días después. Ninguna anotación importante a su respecto hasta un par de semanas más tarde ${ }^{29}$ :

Emawayish, la bella —aunque un poco mustia - princesa de cera. [...] esta mujer de aspecto tan calmo, tan reservado - pese a los eructos potentes que lanza cuando

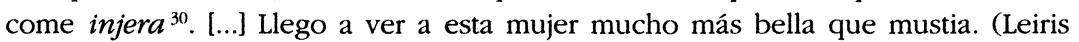
1996: 590. 17.VIII.32).

En este lapso, al mismo tiempo que en el diario aumenta la introspección sexual y que hay una cierta mudanza en las cartas a Zette ${ }^{31}$, en el espíritu del poeta surge un vínculo muy personal con sus "objetos":

${ }^{28}$ De hecho, quienes trabajarían en relación a Malkam Ayyahou serían D. Lifszyc y Leiris; mucho más éste que aquélla. El resto de la Misión estaba por completo ocupado con la historia de las pinturas de la Iglesia de San Antonio y en la compra de manuscritos, pinturas y demás expolios museísticos y tendría una participación marginal y técnica en el estudio: fotografías y filmaciones.

${ }^{29}$ Al día siguiente, Emawayish — de quién todavía no consigna el nombre, sino que la denomina la hija de la patrona de los zar- visitaba el campamento para entrevistarse con Deborah Lifszyc; no es en ella, sin embargo, en quien se fija Leiris, sino en su acompañante, una "vieja poseída con tez de hollín": "[Le] tengo cierta simpatía, debido a sus cabellos crespos, sus dientes blancos mal dispuestos, sus ojos redondos de loca de hospital. El 7.VIII.32 registra la visita de Malkam Ayyahou ("la dama de los $z a m_{\text {) }}$, escoltada por su hija ("la princesa de rostro de cera pero con las tetas mustias"). En esta ocasión, su interés recae más bien sobre otras dos acompañantes, "la bella Dinqqnésh (...) que cada vez más me da la impresión de una putita cualquiera", y la negra Ballatatch que "molesta menos que las otras".

${ }^{30}$ Pan ácimo elaborado con el cereal etíope teff.

31 «No querría de ninguna manera que esta separación que te he infligido sea un simple episodio en nuestra vida. Por el contrario, quiero que marque un punto de 
[...] por más que a veces entro en cólera, estoy ligado a esta gente. La vieja "zarina" me domina como una madre. Sus adeptas son mis hermanas, se den cuenta o no. Amo hasta la falsedad de su posesión, a estas chicas que introducen un poco de fantasía engañosa en sus vidas, escapando a sus maridos y, gracias a sus santos espíritus, se elevan hasta lo irreal que necesitan para olvidar la aplastante masa de jilipolleces habituales (Leiris 1996: 581. 10.VIII.32).

Uno de esos días, el 8 de agosto, en el que anota su añoranza de las épocas en que había prostitución ritual, vierte un ataque de cólera contra su informante cojo y contra Abba Jerôme. La verdadera razón del incidente, confiesa, es el escándalo que le produce el estudio de las cosas ardientes con la frialdad del científico: "la atracción sexual poderosa de las prácticas malditas, al mismo tiempo que el sentimiento muy claro de esta extravagante mentira que es la magian. La magia no sólo tiene vasos comunicantes con el sexo, sino con la poesía: "sin duda, la danza, la poesía, están unidas, para todos los pueblos, a los demonios y a los genios" (Leiris 1996: 572. 2.VIII.32). Leiris se siente así pillado por los cuatro costados por este mundo en el que está entrando. Y además, ¿qué le ofrece el mundo suyo que ha dejado?:

Volver; envejecer; tener detrás de mí lo que tenía delante. [...] ¿Cómo podría volver a vivir en Francia? Para intentar olvidarme, proyecto estudio tras estudio, publicación tras publicación. Pero, iqué miseria, qué fin de todo y qué estrangulamiento de toda esperanza! (Leiris 1996: 595. 22.VIII.32).

El día antes de esta "lúgubre reflexión", Malkam Ayyahou le cuenta que su hija había hecho un primer matrimonio con un dabtara (sacerdote) al que ella había enviado numerosos zar malignos para que, poseyéndolo, le castigaran; el hombre estuvo a punto de morir. Emawayish está, pues, en el centro de este mundo demoníaco; sin embargo, Leiris pretende ponerla un poco como al margen. Aunque no oculte su condición de poseída y de heredera de su madre:

parece siempre un poco incómoda y asustada cuando se habla de esas cosas. Bajo su mugre, parece distinguida y tiene letras... Imagino que debe querer convertirse en la esposa o concubina de un europeo del consulado. Y para eso más vale no ser demasiado demoníaca (Leiris 1996: 594. 21. VIII.32).

Pasan unos pocos días y se produce un acontecimiento clave. Gran velada de posesión que a Leiris le disgusta, dice, por su tumulto, su

inflexión decisivo y que sobre esa base, reconstruyamos todo" (Leiris 1996: 581.carta del 10.VIII.32). Registra también algunos sueños eróticos con su mujer, pero - - como hacen notar tanto Jamin cuanto Mercier- disminuye radicalmente su correspondencia con ella. 
suciedad, su desorden, sus falsos oropeles, sus posesiones falsas. Sin embargo...

Un sólo recuerdo agradable, el de Emawayish, aunque a su aire de princesa se mezcla un cierto lado súcubo, a carne blanda, húmeda, fría, que me repugna al mismo tiempo que me da un poco de miedo. ¿Acaso no está predestinada? ¿Acaso su primer marido, cuando se volvió loco, no se escapaba de casa para ir a aullar a las ruinas de los castillos de Gondar? (Leiris 1996: 596. 24.VIII.32).

Recuerdo también de su primer contacto físico: "Emawayish [...] se extasía con las ropas europeas. Palpa mi 'bush-shirt', mis pantalones cortos de 'bedford', el pantalón a rayas de Abba Jerôme..." (Leiris 1996: 599. 24.VIII.32). Y más: antes, algo alcoholizado, Leiris comete pequeñas aincorrecciones" (las comillas son suyas), quizás no tan pequeñas según recuerda meses más tarde, en Francia, cuando Gondar era ya sólo memoria: “La mano bajo la chamma (túnica) ${ }^{32}$. Y siempre recordaré la entrepierna húmeda, - húmeda como la tierra de la que están hechos los golems" (Leiris 1996: 837; nota de abril de 1933 a anotación del 27.XII.32). Y más aún: canciones de amor de las que no se entera de "más que lo que Abba Jerôme tiene tiempo de traducirme". Éste, "el gran maestro de lo esquivo" (Mercier dixit) da versiones de los versos adulteradas e incompletas a Leiris, quien, de todos modos, presiente que es objeto explícito del deseo de Emawayish y que esas palabras en una lengua que desconoce son la clave de su vínculo con ella.

"Amargura. Resentimiento contra la etnografía que hace asumir esta posición tan inhumana de observador en circunstancias en las que habría que abandonarse", así comienzan las anotaciones del día siguiente, que se siguen con el rumor de que "el último marido de Emawayish - del que se acaba de separar - se arregla con ella. La muchacha no quería porque el hombre es avaro y celoso, pero la han convencido. Además, es el padre del bebén (Leiris 1996: 599. 25.VIII.32). Al otro día envía un doméstico a pedir una entrevista con Emawayish para "completar las canciones anotadas fragmentariamente la otra noche por Abba Jerôme", las canciones de amor cuyas revelaciones "sumen en el delirio" a Leiris. Ésta se niega a recibirlo porque su madre no está en casa. Leiris: "me siento mortificado por esta declaración y pienso que es evidente que las cosas se complican después de la reconciliación" (Leiris 1996: 600.

${ }^{32}$ Esta es una de las pocas auto-censuras del diario publicado; en una hoja de papel intercalada en el cuaderno, dice: "La mano en el culo de Emawayish, la 3." (?) vez que la vin (cit. en Mercier 1994: 34). Por otro lado, en este momento es cuando Leiris comenzó a copiar notas de campo en su diario, confundiendo las dos escrituras que hasta entonces había mantenido separadas. 
25.VIII.32). Pero, albricias, reconciliación no había; la noticia era falsa. Por el contrario, el marido, que había encontrado a Emawayish en su casa tomando café con dos muchachos, había intentado matarla a tiros en un ataque de celos. Un día más tarde, Leiris anota:

Pensando en las fulguraciones incesantes de la vieja, en el encanto insólito que emana de su hija, midiendo el inmenso precio que atribuyo a fijar sus palabras ${ }^{33}$, ya no puedo soportar la investigación metódica. Tengo necesidad de empaparme de su drama, de tocar sus maneras de ser, de bañarme en la carne viva. ¡Al diablo la etnografía! (Leiris 1996: 602. 27.VIII.32).

Sin embargo, lo que en realidad se iría al diablo era el bañarse en carne viva. Lo contrario sería estar disponible para hacerse cargo de Emawayish:

Qué pena no poder hacer nada por esta muchacha, no poder substraerla a la brutalidad de un hombre estúpido. Pero es evidente que para eso habría que hacerse cargo de ella, sustituir a ese hombre, en una palabra: tomarla. Para ello haría falta un hombre disponible y, para que no se convirtiese en una broma ridícula, un hombre que la ame y al que ella pueda amar... Fuera de esto, no se puede hacer nada, y todas las declaraciones de devoción no son más que verborragia platónica" (Leiris 1996: 605. 27.VIII.32).

¿Qué podía hacer Leiris? ¿Regresar a Francia con Emawayish a cuestas? ¿Quedarse en Etiopía con ella? No está, no se siente, en condiciones de hacer ni una cosa ni la otra. No puede "tomar a Emawayish". ¿Sería Abba Jerôme el hombre que iba a hacerlo? Eso es al menos un rumor que le llega a Leiris por Deborah Lifchitz. Anota el día siguiente:

Emawayish está a salvo: hay un hombre que se quiere casar con ella. (Con tal arreglo) ganaré por no ver secarse bruscamente la fuente de poesía y de sellar, de alguna manera, mi pacto con los zar, a los que les debo el desplazarme a unos pies por encima de la tierra, en plena mitología. Y, ¿quién sabe?, si Emawayish viene con nosotros en la caravana, quizás ganaré otra cosa... (Leiris 1996: 605. 28.VIII.32).

Ese mismo día, recibe en el campamento la visita de Malkam Ayyahou y su hija. Están reunidos en su tienda, cuando:

Emawayish siente que el zar pesa sobre los hombros. Está tan incómoda que se quiere alejar más de la madre y me pide permiso para sentarse sobre mi cama. Unos instantes después me coge la mano derecha y la mete bajo su axila para que yo sepa hasta qué punto está ardiente (Leiris 1996: 609. 28.VIII.32).

${ }^{33}$ Es decir, en trabajar con Abba Jerôme en la traducción de sus notas. 
Este episodio, pienso, es el clímax de la relación; desde entonces, Leiris retrocede en el camino de su pasión, no en forma lineal, ya que, como veremos, tiene sus idas y vueltas, pero comienza a poner reservas tanto a Emawayish, cuanto a su madre, al culto zar, en fin, a todo aquello a lo que sabe que debe renunciar. El punto crítico es el de la autenticidad ${ }^{34}$. Los "nativos" no son ni espontáneos, ni inocentes; representan también. $\mathrm{Al}$ igual que en la anécdota del dogon Ambara y el boubou para remendar, absorben al europeo en su lógica, lo usan a sus propios efectos; el más obvio, tomar su dinero.

Un par de ceremonias pagadas por Leiris, según éste se entera más tarde - siempre más tarde-, no han sido realizadas con las precauciones rituales exigidas. Una y otra vez, para estas y otras ceremonias, aumentan las exigencias de objetos que deben ser aportados con dineros de la Misión. Pero lo peor, la inautenticidad se alberga allí donde más alejada debería estar, en los momentos más sagrados del rito. Una ofrenda animal, hecha para Emawayish, pagada por Leiris, termina con la ingestión por parte de aquélla de sangre del animal abatido. Leiris, pensando quizás en las hostias de sus eucaristías infantiles, se escandaliza con el poco agrado mostrado por su "princesa de cera" durante y después de tal acto; la comparación que se le ocurre es, por cierto, significativa:

Me acuerdo de cómo Emawayish se enjugaba la boca después de la taza de sangre, con esa misma ausencia de intento de enmascarar su disgusto que tienen ciertas prostitutas cuando se lavan los dientes tras haber hecho una felación (Leiris 1996: 672. 23.IX.32) ${ }^{35}$.

\footnotetext{
${ }^{34}$ Días después, por ejemplo, interpretará el que se hubiese sentado en su cama como una forma de poder apreciar de cerca las mantas, una de las cuales le terminaría pidiendo.

${ }^{35}$ Sin embargo, años más tarde daría una versión mucho más intensa de este episodio: "Tras haber hecho matar un carnero blanco y rojo para uno de esos genios, la vi jadear en trance -en pleno estado de posesión-y beber en una taza de porcelana la sangre de la víctima que había fluido aún caliente de la garganta cortada. Jamás hice el amor con ella, pero cuando tuvo lugar ese sacrificio me pareció que se establecía entre ella y yo una relación más íntima que cualquier tipo de lazo carnal" (Leiris 1999 [1939]: 199). Por otro lado, Leiris era un entusiasta de burdeles y prostitutas, sobre cuyo carácter cuasi-religioso escribió también en L'âge d'bomme (Ibid.: 59-62). Allí encontramos un fragmento muy parecido al citado de L'Afrique...: "En un museo de escultura o de pintura, siempre me parece que algunos rincones perdidos deben ser teatro de lubricidades escondidas. También sería bueno sorprender a una bella extranjera con impertinente en la mano, que se ve de espaldas contemplando alguna obra maestra y poseerla; ella se quedaría, aparentemente, tan impasible como una devota en la iglesia, o que la vampiro profesional que, después de haber hecho a conciencia el trabajo por el que se le ha pagado, se inclina sobre la blancura del
} 
No es, ni mucho menos, en la combinación entre sacralidad e impureza sexual donde podría naufragar la atracción que siente por los zar y por Emawayish, sino en la simulación dejada de lado por una profesional de la simulación, cuando, la tarea hecha y el dinero embolsado, no hay ya necesidad de fingir deseo y placer, no hay ya necesidad de representar. ¿Cómo evitar la sospecha en una superchería continua? Pero esto no es definitivo. De la irritación de europeo mistificado, Leiris pasa a la resignación: ¿qué más da que las cosas no sean como uno hubiera soñado?:

No reniego de los zar amigos. Ya me han dado más de lo que esperaba de ellos y no puedo juzgarlos más que en el plano de lo maravilloso. Después de todo, ¿qué más da que Malkam Ayyahou embauque o no a sus enfermos, que haga o no de chula, que Emawayish sea una cabezota y una matrona muy dura bajo su aire ingenuo, que las informaciones y los espectáculos que me dan se deban más al deseo de lucro que a una simpatía incluso relativa por un europeo? (Leiris 1996: 655. 18.IX.32).

No son, pues, los etnógrafos los únicos que representan; si Leiris no hubiese tenido un sentido tan fuerte de la culpa, y ya que no había aprovechado la ocasión antes con los dogon, hubiese sido este el momento de descargase del pecado de ser inauténtico frente a seres auténticos. Junto al malestar que el descubrimiento le provoca, Leiris entra en el juego, hace lo que supone que su público nativo espera de él, actúa, representa el «europeon. Comienza a llevar revólver y, con el pretexto de que un desconocido merodea la casa de Malkam Ayyahou, hace el Tartarín y dispara unos tiros al aire. La comedia, sin embargo, está al borde de la tragedia. Los coqueteos entre Emawayish y él son la comidilla pública: por diversos medios le llega el rumor de que "son novios". También deben haberle llegado al airado ex-marido, porque hay una nueva escena de celos: más tiros de los que la mujer consigue escapar, muebles y utensilios del hogar destrozados, en fin, todo un escándalo del que, cosa curiosa, Leiris no parece sentirse para nada responsable.

La admiración física por Emawayish decae en la misma medida en que el mundo espiritual en el que se mueve pierde misterio:

Hace quince días enterarme de que Emawayish estaba habitada por un zar, me hubiera conmovido. Hoy me deja poco menos que indiferente. La magia se ha disipado... ¿Será la sangre de los sacrificios que lo ha borrado todo, al mismo

lavabo para liberar su boca mancillada, después se cepilla vigorosamente los dientes y escupe una vez más, con un ruido blando, lo que todo junto le hace a uno desfallecer y le da frío en el corazón" (Ibidem: 59). 
tiempo que consumado todo? Desde hace poco sé también que Emawayish es abuela. [...] No importa que no tenga, creo, más de 30 años, parece, a mis ojos, menos un súcubo que una matrona. Y sobre todo, a medida que las cosas del zar van perdiendo para mí su misterio, todo se desliza a otro plano. Acabado el frenesí de estas últimas semanas, acabada la posesión, acabado el actuar románticamente (Leiris 1996: 674. 24.IX.32).

La atracción sexual, sin embargo, no abandonará al poeta con tanta facilidad; matizada, continúa:

Emawayish continúa bella y dulce. Y si se olvida - mirando su rostro- su cuerpo acabado de mujer que ha sufrido varios maridos, amamantado no pocos hijos y (lo sé desde hace pocos días) es madre de una hija que está en su segundo casamiento. Uno ya no piensa en sus manías de rácana, en sus discusiones con su madre acerca del agua de Colonia o cualquier otra cosa que tengan que compartir o no compartir, en su acostumbramiento tan pueril a los regalos que ahora ni siquiera considera ya útil agradecer... (Leiris 1996: 654. 18.IX.32) ${ }^{36}$.

La anotación quizás más lúcida, más equilibrada, es aquella en la que se confiesa incapaz de llegar al núcleo de otredad que intuye, pero que, en última instancia, tampoco es tan otra:

Poesías no tan bellas, sin duda, como había creído. Posesión quizás no tan profunda, que se reduce a vagos fenómenos neuróticos, y que sirve también para cubrir su pabellón de no pocas mercaderías. [...] sensación ardiente de estar al borde de algo cuyo fondo jamás tocaré, por no poder abandonarme - como habría que hacerlo- a causa de móviles diversos, muy difíciles de definir, pero entre los que figuran en primer lugar cuestiones de piel, de civilización, de lengua (Leiris 1996: 615. 31.VIII.32).

Leiris opta, pues, por sí mismo, por salvaguardarse. En carta del mismo día a Zette:

Encontrarás en mi diario esta vez cosas que quizás te parezcan un poco locas, pero puedes estar tranquila, que es una locura muy pequeña. El estudio en el

${ }^{36}$ Y también: "Emawayish toca una de las mangas de mi jersey, después detiene la mano en el hueco de mi cuello, debajo de la nuez de Adán y me dice que todavía no estoy tan gordo. Un gesto así, hace no mucho tiempo, me hubiera turbado. Ahora, ni siquiera me irrita. Sin embargo, ni falta que hace decirlo, Emawayish es bella, a pesar de su aspecto de campesina, de piel muy clara pero más bien sucia, engrosada por los partos, arruinada por los amamantamientos, extrañamente curvada por llevar sus hijos a la espalda, a lo que con seguridad debe ese trasero prominente... Su rostro sigue siendo muy fino; sus pies son emocionantes, un poco anchos, pero bien formados y para nada estropeados por andar descalzos por todos los caminos y todos los tiempos" (Leiris 1996: 795. 29.XI.32). 
que me he zambullido se ha apoderado de mí como un mar y a veces me pregunto cómo saldré adelante. Sin embargo, puedes estar segura, siempre salgo adelante $^{37}$ (Leiris 1996: 615. Carta del 31.VIII.32).

La distancia interna que ha erigido frente al zar y frente a Emawayish no le impide - quizás todo lo contrario- aumentar sus visitas a casa de la zarina, visitas que le hacen sentirse cada vez mejor:

Enseguida que llego a casa de Malkam Ayyahou, siento una paz maravillosa. Las adeptas ahora tan familiares, Emawayish tan plácida y tan bella, Malkam Ayyahou, ella misma, tan vivaz a través de todas sus marrullerías y maldades (Leiris 1996: 631. 9.IX.32) ${ }^{38}$.

Las visitas son frecuentes y largas, a menudo hechas con pretextos transparentemente engañosos. A veces no encuentra a Emawayish; otras la encuentra acompañada, lo que le provoca celos (¿Se trata de un pariente, de un pretendiente, de un emisario del marido para la reconciliación?). Siempre el deseo insatisfecho. Una noche que permanece en la casa, mientras todos duermen, él, que ha olvidado traer dónde hacerlo, no lo consigue. Atormentado por chinches y pulgas, pasea por el patio; en uno de los cuartos, con la puerta abierta, su anhelada duerme:

Pienso en reunirme con Emawayish pero tiene a su hijo a su lado; Abba Jerôme en el cuarto. Sin duda, ¿me rechazará? Y tantas otras razones, aunque más no sea la falta de la higiene más elemental... En una palabra, no hago nada (Leiris 1996: 721. 11.X.32).

Nada, que es lo que continua haciendo, aun cuando decida dejar el campamento para pasar varios días en casa de Malkam Ayyahou - todo el tiempo con Abba Jerôme a cuestas, es obvio-. Ve a Emawayish amamantando su hijo, varias veces; unas, sus pechos le parecen odres vacíos, otras "grandes tetas amarillas de loba" (Leiris 1996: 645, n. 137;

${ }^{37}$ Y también: aes una obsesión, pero cuando me haya ido de Gondar ya no pensaré más" (carta del 10.IX.32). Ya fuera de Gondar, una última carta al respecto: "Te juro que no tienes que estar celosa, ni siquiera retrospectivamente. No se trata más que de fantasmas que me han turbado (no voy a negarlo) pero nunca han sido otra cosa más que fantasmas. [...] todo lo que le puede pasar a alguien en un país así se sitúa en un plano tan diferente de nuestro plan común que todo lo que allí pueda ocurrir ocurre en un mundo aparte" (carta del 31.XI.32).

${ }^{38}$ Leiris registra sus sentimientos de familiaridad con el grupo de culto: "Tras el sacrificio a Abba Moras Worqié [un zar] nos hemos hecho casi de la familia. Estamos todo el tiempo con Malkam Ayyahou. En una palabra, formamos parte de la secta. Somos de confianza" (Leiris 1996: 654. 18.IX.32). También: "Como me he hecho gondariano..." (Leiris 1996: 742. 23.X.32). 
nota posterior al registro del 12.IX.32). Pero entre encanto y desencanto, el flirteo continúa. Uno de esos días, tiene lugar la culminación erótica de la aventura, quizás demasiado humilde tras tanto fuego poético: "Es esta tarde cuando recibí de Emawayish la caricia más dulce que me dio: besar en el hueco de la palma de mi mano, que yo había humedecido con agua de colonia y colocado como mordaza sobre su boca" (Leiris 1996: 740 , n. 182; nota de la edición de 1934 al 21.X.32) ${ }^{39}$. Culminación cauta, también podríamos decir. Leiris se había enterado dos días antes de que Emawayish era sifilítica. De todas maneras, siempre le quedó la duda de qué hubiese pasado si se hubiese atrevido $-\mathrm{y}$ si hubiese sido aceptado, lo que no tenemos que dar por hecho- a dar el paso que no dio ("Si me hubiera acostado con Emawayish, quién sabe, tal vez la hubiera podido hacer gozar" [Leiris 1996: 796. 29.XI.32]) ${ }^{40}$.

Como táctica para contrabalancear la atmósfera de la casa de Malkam Ayyahou, Leiris comienza a trabajar con una nueva informante (Dinqié), subordinada de aquella pero con ciertos manejos independientes. Esta mujer, de edad suficiente para tener una hija prostituta, era tuerta de un ojo y con el otro en mal estado. "No se me pasará por la cabeza acostarme con ella. Sin embargo, estoy febril como si se tratase de una cita verdadera" (Leiris 1996: 758. 31.X.32).

Al mismo tiempo, la relación con Malkam Ayyahou y su hija se enfría. Las visitas disminuyen; son ellas las que se aproximan al campamento. A veces, Leiris se niega a verlas; otras, las recibe brevemente, sin afecto. Llega a escatimarles el azúcar para el té con que, gesto de cortesía obligatoria, las convida ${ }^{41}$. En una de estas visitas, después de que su madre hubiese recibido un cuadro regalado por Griaule,

\footnotetext{
${ }^{39}$ En alguna ocasión, en estos últimos momentos de la experiencia, Leiris siente su atracción erótica como una posesión maligna, pero no de un espíritu de Gondar, sino de algo que él traía ya consigo: "Emawayish llega por la noche [...] Tiene el cabello bien peinado y enmantecado y - por primera vez desde que la conozcouna túnica muy blanca. De todas maneras, es una chica a la que quiero (que j'aime bien) y con la que me gusta intentar hablar. ¿Por qué tenía que venir a presentarse frente a mí, al final de este viaje, como si se tratase únicamente de recordarme que estoy poseído interiormente por un fantasma, más malo que todos los zar del mundo?" (Leiris 1996: 733. 18.X.32).

${ }^{40}$ La raíz de la duda de Leiris no caía tanto sobre su competencia sexual —en condiciones normales - como sobre el obstáculo que representaba el ritual de ablación del clítoris por el que su amada había pasado. No es, dice Leiris, que tal mutilación impidiese a estas mujeres gozar del sexo, pero para ello exigía, por parte de sus amantes, una destreza y una potencia sexual mayor de aquella a la que el exiguo parisino aspiraba.

${ }^{41} \mathrm{El}$ interés de los nativos provoca en Leiris dos tipos de reacción. Por un lado, defenderse, a sí y a la Misión, de la amenaza de saqueo: «No quiero que la gente se
} 
Emawayish se despereza y bosteza ruidosamente, como las mujeres a quienes invade la posesión. "El kouragna [=zar] me golpea", dice. Sin duda, su kouragna está celoso de la vieja que acaba de recibir un regalo tan suntuoso... Pasa apenas un minuto cuando Emawayish me coge afectuosamente las dos manos y, en voz baja, me pide perfume. De repente, me siento asqueado más que por cualquier maniobra de puta (Leiris 1996: 766-768. 8.XI.32) ${ }^{42}$.

Queda poco tiempo de Gondar, que los miembros de la Misión viven en gran tensión con las autoridades locales (Caltagirone 1988). El día de la partida - 5.XII.32 - entre los muchos que acuden a ver irse a los franceses, Emawayish lejana; ese día, Leiris dedica más palabras al perro de Deborah Lifszyc que a ella. En el texto que condensaría su comprensión del fenómeno zar, La possession..., no aparecería más que como un personaje marginal. La inmediatez de la pasión y la mediatización del conocimiento no combinan para Leiris.

Tras una ceremonia en casa de Malkam Ayyahou, Leiris anota:

No hablo. ¿A quién hablaría yo? Como las pipas que me dan, bebo el café que me ofrecen. Miro estas tres cosas: el carné de Abba Jerôme, el diafragma del cordero ${ }^{43}$, la rodilla desnuda de Emawayish, y siento más que nunca mi irremediable aislamiento. Es como si estos tres puntos formasen un triángulo en mi ca-

crea con todos los derechos respecto a los fondos de la Misión" (Leiris 1996: 687. 1.X.32). Por el otro, entenderla por la diferencia entre él y esos "otros": "es una locura exigir, en estas condiciones y por parte de gentes para quienes soy tan diferente, desinterés" (Leiris 1996: 689.2.X.32).

${ }^{42}$ Unos días después: "Despacho a Emawayish que ha venido a decirnos adiós y -educadamente- muestra tristeza como en una visita de pésame. A ella, sobre todo, no la puedo soportar... No se va sin haber conseguido dos viejas cajas que hemos abandonado" (Leiris 1996: 778. 17.XI.32).

${ }_{43}$ Una y otra vez, al describir los sacrificios de animales y su posterior despiece, Leiris subraya que un tejido de las vísceras (que nunca termina de saber con exactitud si es el peritoneo o el diafragma y usa un término u otro en diferentes oportunidades) es adherido a una pared de la casa de Malkam Ayyahou. En otras ocasiones, forma parte del tocado con que se adorna la cabeza del agente poseído en un ceremonial específico. "Emawayish con el intestino y el peritoneo del animal cubriendo su cabeza: No pienso en piezas anatómicas, sino en una tiara de mercurio" (Leiris 1996: 645. 12.IX.32). Por curioso que parezca, en la casa de candomblé en la que he llevado a cabo la mayor parte de mi investigación, también se adhería el peritoneo -si ese es en verdad el término; mi ignorancia anatómica no es menor que la de Leiris- sobre paredes o puertas. Es difícil sostener hipótesis difusionistas sobre la relación entre el culto zar y los cultos afrobrasileños, pero no es esta la única similitud que encuentro entre el zar y componentes del campo religioso brasileño. Bastide, por ejemplo, señala en carta a Leiris, que encuentra parecidos con el catimbó, culto de posesión de varios Estados del Nordeste brasileño. 
beza [...], recortasen a mi alrededor el universo con un cuchillo para separarme de él y encerrarme para siempre en el círculo -incomprensible o absurdo para cualquiera- de mis propios encantamientos (Leiris 1996: 688. 1.X.32).

Hoy en día, décadas después de que los triángulos jacobsianos se convirtieran en el pan nuestro antropológico de cada día, la fórmula sería banal o forzada; en 1932, en plena inocencia fonológica, debemos concederle toda su fuerza. ¿Qué subyacía a cada uno de esos vértices? A mi entender: al carné, la etnografía (y la mediación que implicaba la propia presencia de Abba Jerôme) y con ella la distancia del observador; al peritoneo, el absurdo inaceptable de una alteridad irreductible; a la rodilla, el deseo que ha teñido con tanta intensidad la relación de Leiris con el zar. Mantener unidos los tres puntos, y Leiris lo hizo varios meses, era congelar la realidad; mantener unidos los tres puntos era utopía, estar fuera de todo lugar.

Además de ese triángulo, hay una ecuación: el mundo de los zar y Emawayish, metáforas mutuas uno y otra. No es, sin embargo, porque Leiris, tras tanto devaneo e incertidumbre, no se vaya a la cama con ésta por lo que no llega a fundirse en aquél. Lo que creo que ocurrió fue que en Emawayish, y en el deseo que a ella le unía, se condensaba todo aquello que hacía inviable para Leiris su entrega.

El gran gesto hubiera sido dejarse atrapar por la lógica del otro, dejar de ser sí mismo. Apropiarse de esa mujer absurda, de ese súcubo, de esa abuela sifilítica, y que la absurda Abisinia se apoderase de él. Pero Leiris no pudo renunciar ante quien ni siquiera entendería que ha habido renuncia, a qué se ha renunciado y quién lo ha hecho, ante esos indigenas que no comprenden nada de lo que eres y que evidentemente, por más que hagas, nada pueden comprender" (Leiris 1996: 675. carta 26.IX.32). No se puede salir de la propia piel, por peor que se esté dentro de ella ${ }^{44}$;

\footnotetext{
${ }^{44}$ Alguien muy cercano y muy querido de Leiris, el hermano de su madre, "mon oncle l'acrobate", había recorrido a conciencia una escala descendente en la sociedad. Había comenzado como actor de categoría pero, harto del ambiente pedante de los grandes escenarios, pasó a trabajar en obras de capa y espada en teatros de provincia, para elegir después el medio menos artificioso de los café-concert y, por último, del circo. Ascesis en su oficio que era paralela a una ascesis amorosa: "Al mismo tiempo que se operaba lo que para su medio burgués no era más que una ruina, ponía término a una agitada vida amorosa con un casamiento idiota y luego con un amancebamiento aún más idiota, prefiriendo a mujeres que les eran muy superiores en todos los sentidos, dos brutas estúpidas, la primera de las cuales —una campesina escapada muy joven de su casa con una troupe de feriantes chinos- había sido primero traga sables y luego bailarina en la cuerda floja. Bonita de cuerpo, retenía a mi tío que 'la llevaba en la piel'; pero acabó por asquearse de su sensualidad bestial,
} 
la noche de las "incorrecciones" y de los poemas de amor, del deseo suelto en el aire, un puñado de servidores nativos de la Misión asiste a la fiesta de las poseídas. Leiris reflexiona:

Evalúo muy bien hasta qué punto me despreciarían si descendiese a su nivel, si me dejase ir... Qué horrible es ser europeo, a quien no se ama pero a quien se respeta mientras quede amurallado en su orgullo de semidiós y a quien se escarnece desde que quiera aproximarse (Leiris 1996: 599. 24.VIII.32).

Según Izard (1983: 140) la redacción del diario le ayudó a detenerse a tiempo ante el abismo ${ }^{45}$. Quizás. También podemos pensar que Leiris construyó un abismo con los suficientes parapetos como para solazarse a su borde sin demasiados peligros; es decir, que Leiris hizo trampa eligiendo a Emawayish como objeto de amor (im)posible. Nunca lo sabremos. Tampoco lo habrá sabido Leiris.

Lo que sí supo: los cultores del zar son tan comediantes como los etnólogos, como los dogon, o como los camareros de café; la actuación, la representación, la inautenticidad, es - para usar terminología de Sartre, de quien se sentiría después tan próximo- elemento central de la condición humana ${ }^{46}$. Además: la representación de la escritura es incompatible

más aún porque — sufriendo por ser mayor que él- casi lo volvía loco con sus celos. [...] La concubina que la reemplazó era fea, de una fealdad indecente; aún más tonta, si era posible, lo acosaba con sus enredos interminables y se burlaba ofensivamente de éln (Leiris, 1999 [1939]: 77). Pero a Leiris le faltaba el valor de una elección semejante, una elección de vida y no la puntual relación con prostitutas y mujeres que "estaban por debajo" de él: "Sin querer compararme con él desde el punto de vista del coraje, me siento muy cercano de este tío que buscó toda su vida [...] lo que para otros no era más que una caída y recogió a sus mujeres, una del aserrín de las pistas, la otra casi de la calle, tanto le gustaba lo desnudo y auténtico, tanto debía también encontrar alegría en sacrificarse (Ibid.: 78).

${ }^{45}$ Hay quien sí salta; es el caso - habrá otros- de estudiosos de cultos afro-americanos que se convirtieron en integrantes, y hasta en agentes, de los mismos. Sin embargo, del otro lado del espejo las cosas quizás no sean tan diferentes, como lo dice Gisele Cossard-Binon, antropóloga de la Sorbonne y sacerdotisa del candomblé en los suburbios de Rio de Janeiro: "El problema de Pierre (Verger), de Bastide, de Métraux, de Lydia (Cabrera), mi problema: Huímos para experimentar otro mundo, más voluptuoso, más agradable, y descubrimos que es más burgués que el mundo que habíamos abandonado" (Fichte, 1987: 86).

${ }^{46}$ Sartre (1943: 98) presenta una larga descripción fenomenológica de un camarero que juega (actúa) a ser camarero («Pero, ¿qué somos pues, si tenemos la obligación constante de hacernos ser lo que somos, si somos en el modo de ser del deber ser lo que somos?" énfasis de JPS ). Fabre (1999: 219) nos insta a no tomar a la ligera la cercanía con Sartre reconocida por Leiris (Price y Jamin 1988: 63). Este autor también 
con una presencia inmediata -e inimaginable, o tal vez, tan sólo imaginable-. Por otra parte: el silencio al que no había podido optar, ¿le hubiese quizás transportado a lo maravilloso? ¿Habrá sido ese el destino de Rimbaud, o sólo fue ignominia, desesperación y muerte gangrenada? ¿Quién lo podría decir? Representación —es decir, teatralidad- de la vida - de toda vida, de cualquier vida-, representación —es decir, presentación diferida de la narrativa, de toda narrativa, de cualquier narrativa-, eso quedó de la Dakar-Yibuti para Leiris. Sus posteriores desarrollos sobre la posesión como teatro ${ }^{47}$, que implicarían un aporte esencial en la teoría antropológica sobre el tema, derivan de esta experiencia.

La protagonista, también marchita, de Hiroshima mon amour, la película de Alain Resnais sobre texto de Marguerite Duras - tan lejana, tan cercana a Leiris ${ }^{48}$ - dice a su circunstancial amante japonés que le pide que dé el gran salto y se quede con él: "te convertirás en una canción". Emawayish, ella, se convirtió en un bello poema:

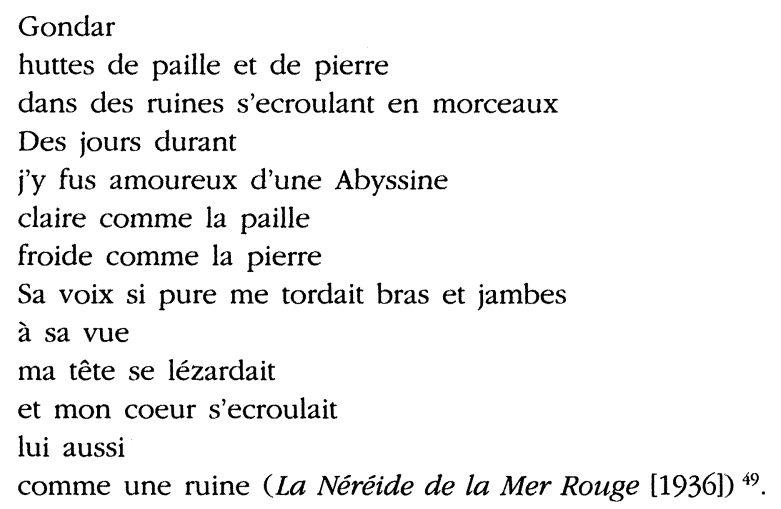

dice: “Toda investigación etnográfica lúcida e inventiva se nutre de su propia inautenticidad pero la conciencia de ésta no induce obligatoriamente al cinismo; puede, por el contrario, mantener constante y dolorosamente alerta.

${ }^{47}$ L'Afrique... se convirtió, por intermedio de Geneviève Rosset, en obra de teatro, representada en octubre de 1997 en el Teatro Nacional de Addis Abeba y un año más tarde en el Teatro Internacional de Lengua Francesa en París.

${ }^{48}$ En Armel (1996) encontramos una comparación entre las estrategias autobiográficas de ambos que así termina: “ $i$ si la literatura tal como la han practicado Marguerite Duras y Michel Leiris no tuviera como finalidad - cualesquiera que fuesen los meandros a los que los conducían las estrategias de la confesión- más que tender a lo indecible?n.

49 Veamos otra referencia de pocos años más tarde: «Muy bella de rostro pero con el pecho devastado, se cubría con una toga de un blanco generalmente más que dudoso, olía a leche agria y tenía una joven negra esclava; se diría una estatua de 
La idea que de todo esto me surge es que Emawayish fue para Leiris lo que Ogotemmêli fue para Griaule, en forma inversa y simétrica, para decirlo "à la Lévi-Strauss". El joven poeta desencantado y la abuela sifilítica que danza poseída con el intestino de una cabra en la cabeza, por un lado, $y$, por el otro, el maestro etnógrafo y el sabio de sutil filosofía exótica.

El episodio Emawayish hace que Leiris entienda por fin que la única autenticidad es la inautenticidad, la representación. El episodio Ogotemmêli hace que Griaule se construya en la más radical de las inautenticidades, aquella que representa la autenticidad. Leiris se acepta europeo; Griaule se inventa dogon.

\section{BIBLIOGRAFÍA CITADA}

ARMEL, A. 1996. "L'écriture et la vie dans les stratégies de l'aveu chez Marguerite Duras et Michel Leiris". Gradbiva 20: 43-49.

BYrNE, A. 2001. "La quête d'une femme ethnologue au coeur de l'Afrique coloniale. Denise Paulme. 1909-1998. Clio en Afrique 6.

Calame-Griaule, G. 1987 (1965). Ethnologie et langage. La parole chez les Dogon. Paris: Institut d'ethnologie.

CALTAGIRONE, B. 1988. "Le sejour en Éthiopie de la mission Dakar-Djibuti”. Gradhiva 5: 3-11.

Clifford, J. 1995 (1984). "Cuéntame tu viaje: Michel Leiris". Dilemas de la cultura: Barcelona. Gedisa.

Cogez, G. 1999. "Objet cherché, accord perdu. Michel Leiris et l'Afrique». L'Homme 151.

Comelles, J. M. 1992. "Lejos de los árboles. A modo de respuesta". Antropología 3: 143-155.

CONDOMinAS, G. 1991 (1965). Lo exótico es cotidiano. Barcelona: Júcar.

DERIVE, J. 1998. "Un voyage ethnographique dans l'Afrique coloniale: L'Afrique fantôme de Michel Leiris", en Fonkoua (ed.), Les discours de voyages. Afrique-Antilles. Paris: Karthala.

DesColA, Ph. 1993. Les lances du crépuscule. Relations Jivarons, Haute Amazonie. Paris: Plon.

DupuIS, A. 1987. "Presentación" a "Correspondance de Deborah Lifchitz et Denise Paulme avec Michel Leiris. Sanga, 1935". Gradbiva 3: 44-45.

FABRE, D. 1999. “Un rendez vous manqué. L'Homme 151.

Fichte, H. 1987. Etnopoesia. Antropologia poética das religiões afro-americanas. São Paulo: Brasiliense.

cera, y los tatuajes azulados que rodeaban su cuello le alzaban la cabeza como lo hubiese hecho un cuello postizo o la picota de una tortura muy antigua dejando a las pieles su marca como un bordado. [...] Amputada de su clítoris como todas las mujeres de su raza, debía ser frígida, al menos en lo que concierne a los europeos (Leiris 1999 [1939]: 199). 
Giobeluina Brumana, F. 2000. "Artaud entre los tarahumara: una etnografía delirante". Cuadernos Hispanoamericanos 603.

IZARD, M. 1983. "L'Afrique Fantôme de Michel Leirs". Les Temps Modernes.

JAMIN, J. 1994. "Documents et le reste... De l'Anthropologie dans les bas-fonds". Revue des revues 18.

- 1996. "Introduction à Miroir de l'Afrique", Miroir de l'Afrique: Paris: Gallimard.

Leiris, M. 1933. "Danses funéraires dogon (extrait d'un carnet de route). Minotaure 1: 73-76.

- 1948. La langue secrète des Dogons de Sanga. Paris: Institut d'ethnologie. Collection "Travaux et Memoires de l'Institut d'ethnologie".

- 1969 (1956). "À travers 'Tristes Tropiques'. Les Cabiers de la République 2: 130-135.

- 1991 (1967). "Titres et Travaux". Gradhiva 9: 5-13.

- 1993 (1939). "Compte rendu des activités du Collège de sociologie". Gradhiva 13: 67-69.

- 1996 (1934). Afrique Fantôme, en J. Jamin (ed.), Miroir de l'Afrique. Paris: Gallimard.

- 1996a (1983). "Encens pour Berhanê", en J. Jamin (ed.), Miroir de l'Afrique. Paris: Gallimard.

- 1999 (1939). L'âge d'bomme. Paris: Gallimard.

Lejeune, PH. 1986. "Post-scriptum", en Moi aussi. Paris: Ed. Du Seuil.

LÉvi-STRAuss, C. 1955. Tristes Tropiques. Paris: Plon.

LÉvi-Strauss, C. y D. ERIBON. 1990. De près et de loin. Paris: Points.

LIFCHITZ, D. y D. PAulme. 1987 (1935). “Correspondance de Deborah Lifchitz et Denise Paulme avec Michel Leiris. Sanga 1935". Gradhiva 3: 44-58.

MALINOWSKI, B. 1989 (1966). Diario de campo en Melanesia. Madrid: Júcar.

MARTINO, E. DE. 1999 (1961). La tierra del remordimiento. Barcelona: Bellaterra.

MERCIER, J. 1994. "Journal intime et enquêtes ethnographiques. Les traverses éthiopiennes de Michel Leiris". Gradbiva 16: 29-42.

Paulme, D. 1940. Organization sociale des Dogon. Paris: Domat-Montchrestien.

PeiXoto, F. 1992. "O nativo e o narrativo. Os trópicos de Lévi-Strauss e a Africa de Michel Leiris". Novos Estudos CEBRAP 33.

- 1998. "Lévi-Strauss no Brasil: a formação do etnólogo". Mana. Estudos de Antropologia Social 4. 1.

PRICE, S. y J. JAMIN. 1988. "Entretien avec Michel Leiris". Gradbiva 4.

RABINOW, P. 1992. Reflexiones sobre un trabajo de campo en Marruecos. Madrid: Júcar. SARTRE, J. P. 1943. L'être et le néant. Paris: Gallimard.

SCHAEFFNER, A. 1991 (1932). "Lettre inédite a Michel Leiris (21 février 1932)". Gradbiva 9: $14-15$.

SEITÉ, Y. 1999. "L'âge du jazZ”. Gradbiva 25: 27-44. 